\section{Regulators' agreement on better sharing of information}

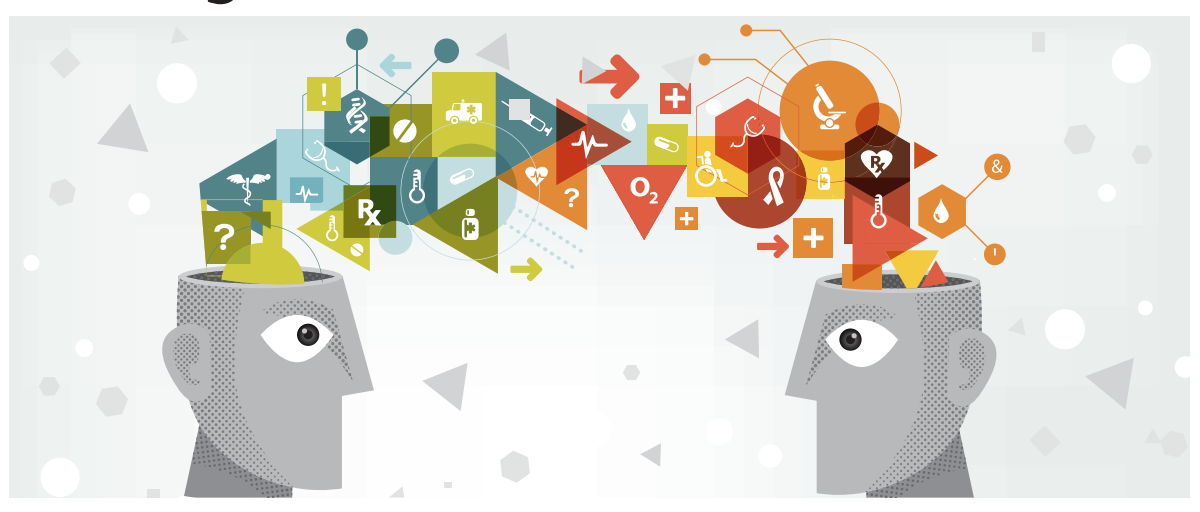

Eight of the health and social care profession regulators have all signed a new protocol designed to ensure information is consistently shared quickly and effectively to enhance coordination.

The Emerging Concerns Protocol ${ }^{1}$ strengthened existing arrangements, providing a clear mechanism for organisations to raise concerns and arrange meetings where they can be discussed, said the regulators.

Organisations that have signed the protocol include:

- Care Quality Commission (CQC)

- General Medical Council

- General Pharmaceutical Council

- Health and Care Professions Council

- Health Education England

- Local Government and Social Care Ombudsman

- Nursing and Midwifery Council

- Parliamentary and Health Service Ombudsman

Dentists' regulator the GDC is said to be supportive of the emerging concerns working group for the protocol and is set to become a signatory in the near future. The GDC is working with the working group, as is NHS England and NHS Improvement.

The protocol is described by the parties as an evolving agreement that looks to build on strong existing relationships.

It was developed by a working group and piloted with operational staff from all organisations involved. The work was commissioned by the Health and Social Care Regulators' Forum, which oversees its progress.

The protocol document gives an example of how it can be used. It involved a senior doctor working in the NHS who approached ๑ a General Medical Council regional liaison adviser at a conference to mention that they had experienced issues for several months with the quality of surgical equipment used by their organisation.

'The issue was clearly an urgent patient safety concern and involved doctors, nurses and other healthcare professionals. The organisations' senior management were aware,' says the document.

'This disclosure was clearly about a live and ongoing patient safety concern that went beyond the GMC's statutory functions and was potentially affecting at least three professional groups and a number of NHS and private healthcare organisations.

'It was determined by GMC senior managers that this information had to be shared urgently with CQC [Care Quality Commission] and other partners.'

This happened and regulatory action was agreed and taken swiftly by CQC.

Professional regulators shared intelligence and data, while the Health and Safety Executive and Medicines and Healthcare products Regulatory Agency was briefed.

A spokesperson for the CQC said: 'We know that sharing concerns at the right time can make it easier to notice that a problem is emerging. We believe that working together more effectively can reduce duplication by encouraging our organisations to come up with joint plans when we share similar concerns.'

The protocol only covers England, so the regulators with responsibility for regulating across the UK or Great Britain will continue to work collaboratively with the relevant national organisations in the devolved countries.

1. Care Quality Commission. Emerging Concerns Protocol (August 2018). Available at https://www.cqc.org.uk/ sites/default/files/20180726_emerging-concerns-protocol.pdf (accessed 6 August 2018).

\section{f34 million boost for dental services}

People across Lincolnshire are set to benefit from improved access to local NHS dental care after NHS England (Central Midlands) awarded five new contracts to dental service providers.

The contracts, which include provision of four new dental practices in Spalding, Sleaford, Boston and Lincoln, plus a replacement for the former NHS dental service at Johnson Community Hospital in Pinchbeck, represent an annual investment in local dental care of $£ 3.39$ million, totalling almost $£ 34$ million over the 10-year contract period.

When they come into effect from January 2019, the contracts - which run for seven years with the option for NHS England to extend for a further three years - will provide a total of 116,000 Units of Dental Activity (UDAs) to NHS patients every year.

Bids were also invited to provide extended access dental services in Louth and the Skegness/Spilsby area (total 15,000 UDAs), but these two contracts were not awarded because the bids did not meet NHS England's criteria.

NHS England said the new contracts had been commissioned in response to an assessment of local dental needs in Lincolnshire. This assessment identified priority areas where improved access to NHS dental services was required.

The exact locations of the new practices within each area will be agreed between NHS England and the service providers.

Di Pegg, Head of Primary Care for NHS England in Lincolnshire, said: 'Having looked at the overall picture in Lincolnshire and gained an understanding of which areas are most in need of better access to dental care, we're delighted to confirm that a range of new NHS practices will be launching in January across the county.

'It's disappointing that we've not been able to award contracts for new services in Louth or the Skegness and Spilsby area as we'd hoped, but we will be renewing our focus on improving access to NHS dental care in these areas as soon as possible.' 